\title{
ENSEÑAR LA HISTORIA CONTEMPORÁNEA \\ A TRAVÉS DEL CINE DE FICCIÓN
}

\author{
J. M. CAPARRÓS LERA \\ Centre d'Investigacions Film-Història \\ Universidad de Barcelona
}

Que el arte cinematográfico es un testimonio de la sociedad de su tiempo, hoy nadie lo duda. Es más, el film es una fuente instrumental de la ciencia histórica, ya que refleja, mejor o peor, las mentalidades de los hombres de una determinada época. Además, las películas pueden ser un buen medio didáctico para enseñar la historia contemporánea.

Obviamente que la evocación de la Historia ha supuesto para el cine uno de los géneros primigenios y más populares. En la actualidad, el film histórico se confunde con el cine de ficción, pues toda película es de algún modo histórica, viene a ser -diría el primer especialista Marc Ferro- un "contra-análisis de la historia oficial"; pues no interesa tanto el rigor de la reconstitución del pasado, sino cómo ven ese pasado los cineastas de hoy, influidos por lo que se piensa del ayer en ciertos estratos de la sociedad del momento. A veces -añadiría su colega Pierre Sorlin-, las películas nos "hablan más de cómo es la sociedad que las ha realizado" que del referente histórico que intentan evocar.

Este discurso introductorio no resulta gratuito si queremos aproximarnos a las nuevas vías de investigación del cine mundial, si pretendemos coger -nunca mejor dicho"el tren de la Historia". Pues es bien conocido que a partir de los años setenta y, sobre todo, durante la pasada década, una serie de historiadores han ido acometiendo el estudio del fenómeno cinematográfico desde unas perspectivas más sociológicas que estrictamente fílmicas. Por otra parte, el estudio del cine como mero arte es, hoy por hoy, una materia algo estática; mientras que su profundización como reflejo de las mentalidades de la sociedad y como materia auxiliar de la Historia resulta una ciencia más dinámica, en constante evolución y desarrollo metodológico. Sobre el arte de las imágenes fílmicas -movimientos, estilos, escuelas, grandes autores... - está casi todo prácticamente escrito y discutido, pero acerca de sus posibilidades investigativas -las relaciones entre Cine e Historia-, queda mucho camino por andar; es más, resulta todavía un pozo sin fondo.

De ahí que, en el año 2005, Peter Burke -uno de los más prestigiosos historiadores de la Cultura- se pronunciase así: 
Dada la importancia que tienen la mano sujeta a la cámara, y el ojo y el cerebro que la dirigen, convendría hablar del realizador cinematográfico como historiador. La capacidad que tiene una película de hacer que el pasado parezca estar presente y de evocar el espíritu de tiempos pretéritos es bastante evidente.

En otras palabras, el testimonio acerca del pasado que ofrecen las imágenes es realmente valioso, complementando y corroborando el de los documentos escritos. Muestran ciertos aspectos del pasado a los que otros tipos de fuentes no llegan ${ }^{1}$.

\section{Primeros investigadores}

Aparte del pionero Siegfried Kracauer, que en 1947 sorprendió a los teóricos con un sugerente y debatido ensayo sobre el cine de la República de Weimar (From Caligari to Hitler. A Psychological History of the German Film. Princeton University Press) $)^{2}$, el primer especialista sobre este nuevo enfoque del cine histórico es, sin duda, el citado historiador de la escuela de Annales Marc Ferro. De él escribió su coetáneo, el también referido Pierre Sorlin:

Si algún día la historiografía francesa reserva un lugar al cine, a él se lo deberemos. Consejero histórico, después realizador, técnico al mismo tiempo que historiador, [Ferro] ha visto las dificultades que se habían escapado a sus predecesores, y sus escritos empiezan a prolongar a Kracauer, superándolo. Más que como copia de la realidad, la imagen le parece un revelador: "la cámara revela el secreto, muestra el anverso de una sociedad, sus lapsos"...

El cine [...] abre perspectivas nuevas sobre lo que una sociedad confiesa de sí misma y sobre lo que niega, pero lo que deja entrever es parcial, lagunario y sólo resulta útil para el historiador mediante una confrontación con otras formas de expresión ${ }^{3}$.

Ciertamente, Marc Ferro es el maestro de la utilización del arte cinematográfico como fuente de la ciencia histórica y como medio didáctico de la Historia Contemporánea. Sus primeras investigaciones datan de la década de los sesenta, en colaboración con Annie Kriegel y Alain Besançon, en torno a un tema del que él es especialista ${ }^{4}$. A continuación, siguieron sus trabajos en Annales, donde con el ensayo titulado "Société du XXè siècle et Histoire cinématographique" se advierte una doble tendencia investigativa: el reflejo de los

\footnotetext{
${ }^{1}$ Burke, P. Visto y no visto. El uso de la imagen como documento histórico. Barcelona, Crítica, 2005, pp. 201 y ss.

${ }^{2}$ Vid. la última edición española: Kracauer, S. De Caligari a Hitler. Una historia psicológica del cine alemán. Barcelona, Paidós, 2001.

${ }^{3}$ Sorlin, P. Sociología del Cine. La apertura para la historia de mañana. México D.F., Fondo de Cultura Económica, 1985, p. 43.

4 “Histoire et Cinéma: L'experience de "La Grande Guerre"”, en Annales, 20 (1965), pp. 327-336.
} 
hechos sociales en el cine y el rigor crítico en el análisis histórico ${ }^{5}$. Asimismo, en el volumen editado por Paul Smith, The Historian and Film, Ferro incluye un artículo revelador: "The fiction film and historical analysis", aplicando su metodología a una película representativa -Tchapaiev (1934), de Vassiliev, obra fundamental de la época estalinista-, a través de la cual se pueden percibir las claves socio-históricas que configuran el film, junto a las peculiaridades que presenta esta obra dentro de su contexto político ${ }^{6}$. Finalmente, la obra básica de Marc Ferro, Cine e Historia -que ya ha visto la luz en varios idiomas- fue reeditada y aumentada en su original francés (Cinéma et Histoire. París, Gallimard, 1993) y nuevamente publicada en lengua castellana bajo el título de Historia contemporánea y cine (Barcelona, Ariel, 1995; nueva edición en 2000), por iniciativa del Centre d'Investigacions Film-Història de la Universidad de Barcelona (UB) y prologada por el que suscribe ${ }^{7}$.

Entre los teóricos coetáneos franceses cabe citar a los historiadores Annie Goldman, Joseph Daniel y René Prédal ${ }^{8}$, junto al equipo del Institut Jean Vigo, de Perpignan, que encabezaría el desaparecido Marcel Oms (con la revista Les Cahiers de la Cinémathèque y sus Confrontations especializadas); al tiempo que destacaría el referido Pierre Sorlin, catedrático de Sociología del Cine en la Université de la Sorbonne Nouvelle y antiguo presidente de la International Association for Media and History (IAMHIST), de Oxford, donde asimismo impartió un curso monográfico sobre las relaciones entre Cine e Historia ${ }^{9}$. Posteriormente, este reconocido investigador publicaría otra visión sociológica del cine de los últimos años: Cines europeos, sociedades europeas, 1939-1990 (Barcelona, Paidós, 1996).

\footnotetext{
${ }^{5}$ Cfr. Annales, 23 (1968), pp. 581 y ss.

${ }^{6}$ En Smith, P. (ed.) The Historian and Film. Cambridge: Cambridge University Press, 1976, pp. 80-94; así como su primer libro Analyse de film, analyse de sociétés. Un source nouvelle pour l'Histoire. París, Hachette, 1975, donde afirma: "De todas maneras, cada film tiene un valor como documento, no importa del tipo que sea... El cine, sobre todo el de ficción, abre una vía real hacia zonas socio-psicológicas e históricas nunca abordadas por el análisis de los documentos". Vid. también la monografía de F. Garçon, Cinéma et Histoire (autour de Marc Ferro). París, CinémAction/Corlet, 1992.

${ }^{7}$ Esta obra fue el libro de texto de la asignatura que instauré en la UB, en 1995, y cuando obtuve la plaza de Profesor Titular en esta materia -Història Contemporània i Cinema, en 1997publiqué mi manual: 100 películas sobre Historia Contemporánea (Madrid, Alianza, 1997; 2a ed. 2004).

${ }^{8}$ La société française 1914-1945 à travers le cinéma. París, Armand Colin, 1972.

${ }^{9}$ Sorlin, P. The Films in History. Restaging the Past. Oxford, Blackwell, 1980.
} 


\section{Escuelas anglo-europea y norteamericana}

Y ya que citamos a la IAMHIST -organismo internacional que reúne a los principales especialistas sobre el tema-, cabe destacar también la gran tradición de diversas escuelas historiográficas. La más importante está situada en Oxford, bajo el impulso primigenio del asimismo pionero británico y hoy desaparecido David J. Wenden ${ }^{10} \mathrm{y}$ de los ingleses Paul Smith -quien, con el ya mencionado "estado de la cuestión" The Historian and Film, pondría las bases-, Nicholas Pronay, Richard Taylor, Jeffrey Richards y Anthony K. Aldgate, junto al fundador de la revista de investigación Historical Journal of Film, Radio and Television Kenneth R. M. Short ${ }^{11}$. Otras escuelas centro-europeas se desarrollarían alrededor de los especialistas Kastern Fledelius, Van Peet, Frans Nieuwenhof, Wilhelm van Kampen o Stephan Dolezel (Institut für den Wissenschaflichen Film, de Göttingen), entre otros historiadores que trabajan en Italia, como el británico David W. Ellwood.

Asimismo, en Estados Unidos, The Historians Film Committee es la entidad que ha capitaneado las investigaciones sobre el tema. Cofundada por Martin A. Jackson, gran pionero en aquel país, este teórico manifestó en 1974 ante la UNESCO:

Es imposible comprender la sociedad contemporánea sin referirse a los filmes que se han venido realizando desde hace 70 años. El cine, y no debemos cansarnos de repetirlo, es una parte integrante del mundo moderno. Aquel que se niegue a reconocerle su lugar y su sentido en la vida de la humanidad privará a la Historia de una de sus dimensiones, y se arriesgará a malinterpretar por completo los sentimientos y los actos de los hombres y mujeres de nuestro tiempo ${ }^{12}$.

Y junto al profesor Jackson, cabe destacar a John O'Connor, antiguo editor de la revista especializada Film and History ${ }^{13}$, así como a los profesores David Culbert, Richard Raack, John Wiseman, Peter C. Rollins ${ }^{14}$ y un largo etcétera. También cabe destacar a los

\footnotetext{
${ }^{10}$ Vid. su libro The Birth of the Movies. Londres: McDonald, 1974.

${ }^{11}$ Cfr. su importante obra de edición, Feature Films as History. Londres, Croom Helm, 1981.

${ }^{12}$ Jackson, M. A. "El historiador y el cine", en Romaguera, J. \& Riambau, E. (eds.) La Historia y el Cine. Barcelona, Fontamara, 1983, p. 21.

${ }^{13}$ Vid. también el libro de O'Connor, J. E. \& Jackson, M. A. (eds.) American History/ American Film. Interpreting the Hollywood Image. Nueva York, Frederick Ungar, 1988.

${ }^{14}$ Actual director de la citada revista Film and History, coordinó un importante libro: Hollywood: el cine como fuente histórica. La cinematografía en el contexto social, político y cultural. Buenos Aires, Fraterna, 1987.
} 
especialistas Carl J. Mora y John Mraz; el canadiense Ian C. Jarvie ${ }^{15}$ y el norteamericano Robert A. Rosenstone (Revisioning History: Filmmakers and the Construction of a New Past. Princeton University Press, 1994; Visions of the Past: The Challenge of Film to the Idea of History. Harvard University Press, 1995) ${ }^{16}$. Sin embargo, al profesor Rosenstone que acaba de publicar otra obra clave: Film on History/History on Film (Londres, Pearson Educational, 2006)- le interesa primordialmente cómo las películas explican y se relacionan con la Historia y no cómo la reflejan; aspecto último en que trabajan los referidos colegas europeos Marc Ferro y Pierre Sorlin.

Posteriormente, a estos autores y obras se ha añadido otros libros básicos: S. Mintz, S. \& R. Roberts, (eds.), Hollywood's America: United States History through its Films (Nueva York, St. James, 1993); L. Grindon, Shadows on the Past. (Philadelphia, Temple University Press, 1994); y T. Mico, J. Miller-Monzon, \& D. Rubel, Past Imperfect: History According to the Movies. Henry Holt \& Co., 1995; y el reciente manual del profesor Shlomo Sand, El siglo XX en pantalla. Cien años a través del cine (Barcelona, Crítica, 2005), o los libros de los españoles Emilio Carlos García Fernández, Cine e historia. Las imágenes de la historia reciente (Madrid, Arco, 1998); María Antonia Paz y Julio Montero, El cine informativo 1895-1945. Creando la realidad (Barcelona, Ariel, 2001); los editados por Gloria Camarero, La mirada que habla. Cine e ideologías (Madrid, Akal, 2002) y Julio Montero \& Araceli Rodríguez, El cine cambia la historia (Madrid, Rialp, 2005), aparte de los volúmenes de Santiago de Pablo, La historia a través del cine, procedentes de las Jornadas especializadas que este catedrático dirige en la Universidad del País Vasco (Vitoria).

\section{Más allá de los géneros}

Resulta evidente, pues, que el arte de las imágenes fílmicas es un testigo implacable de la Historia Contemporánea, como medio de investigación y material para la enseñanza de esta asignatura o interdisciplinaria con otras (véase al respecto José Enrique Monterde et

\footnotetext{
${ }^{15}$ Es autor de dos reconocidos estudios sociológicos: Sociología del cine. Madrid, Guadarrama, 1974; y El cine como crítica social. México D.F., Prisma, 1979, además de la importante obra Philosophy of the Film. Londres, Routledge \& Kegan Paul, 1987.

${ }^{16}$ Este último publicado en España bajo el título de El pasado en imágenes. El desafío del cine a nuestra idea de la historia. Barcelona, Ariel, 1997, y también promovido por el Centre d'Investigacions Film-Història. Editor en Estados Unidos de la revista Rethinking History, dirigió durante años una sección especializada -"Film Reviews"- en la prestigiosa The American Historical Review.
} 
al.; La interpretación cinematográfica de la historia, Madrid, Akal, 2001; y J. Fernández Sebastián, Cine e Historia en el Aula, Madrid, Akal, 1989). Pues pocos medios de comunicación subrayan mejor la actualidad del mundo en que vivimos, ya que las palpitantes imágenes de las películas testimonian el acontecer de los pueblos, reflejan las mentalidades contemporáneas. De ahí que el desaparecido maestro del neorrealismo, Roberto Rossellini, declarara en 1963:

La historia, a través de la enseñanza audiovisual, puede moverse en su terreno y no volatilizarse en fechas y nombres. Puede abandonar el cuadro historia-batalla para construirse en sus dominantes socio-económico-políticas. Puede construir no en la vertiente de la fantasía, sino en la de la ciencia histórica: climas, costumbres, ambientes, hombres..., que tuvieron relieve histórico y promovieron los avances sociales que hoy vivimos. Algunos personajes, regenerados psicológicamente, pueden convertirse por sus cualidades humanas en módulos de acción ${ }^{17}$.

Largo discurso de Rossellini que se concretaría en ese singular "cine didáctico" realizado para la televisión.

Por otro lado, sin llegar al maximalismo del norteamericano David Wark Griffith -quien en 1915 manifestó: "Llegará un momento en que a los niños en las escuelas se les enseñe prácticamente todo a través de películas; nunca se verán más obligados a leer libros de Historia"-, el profesor y realizador belga André Delvaux publicó ya en 1961 un revelador artículo titulado "Le cinéma et l'histoire contemporaine", base de su ponencia sobre el tema presentada en la XXVII Semana Social Universitaria de Bruselas (Simposium celebrado en el Institut de Sociologie de Solvay, 20-25 abril de 1959), que prácticamente sería la primera "pica en Flandes" en este terreno ${ }^{18}$.

En España, con todo, también han surgido otros especialistas aparte de los ya mencionados: el pionero es Ángel Luis Hueso, con su libro fundamental El cine y el siglo XX (Barcelona, Ariel, 1998) ${ }^{19}$, así como Juan Carlos Flores Auñón (El cine, otro medio didáctico. Introducción a una metodología para el uso del cine como fuente de las Ciencias Sociales. Madrid, Escuela Española, 1982) y Joaquim Romaguera \& Esteve Riambau, o el fundador del citado Centre d'Investigacions Film-Història -precisamente el autor de este artículo- y editor desde 1991 de la revista FILM-HISTORIA -primero en

${ }^{17}$ Citado en Caparrós Lera, J. M. El cine político visto después del franquismo. Barcelona, Dopesa, 1978, p. 9.

${ }^{18}$ Vid. asimismo el trabajo del etnólogo Luc de Heusch, Le cinéma comme science sociale. París, UNESCO, 1962.

${ }^{19}$ La primera edición data de 1983, basada en su tesis doctoral El cine, fuente histórica del siglo XX (1974). 
papel y después online (www.pcb.ub.es/filmhistoria)-, que ha ido impulsando una escuela de historia contextual del cine -siguiendo la denominación anglosajona: cinematic contextual history- en el seno del Departamento de Historia Contemporánea de la UB. Allí celebramos en febrero de 1992 el Congreso Internacional sobre Guerra, Cine y Sociedad, que constituyó la "puesta de largo" de este grupo investigador ${ }^{20}$, y ahora también editamos una colección de libros, en la cual ya ha visto la luz la obra colectiva El cine en Cataluña. Una aproximación histórica (Barcelona, PPU, 1993), la tesis doctoral de Sergio Alegre, El Cine cambia la Historia. Las imágenes de la División Azul (Barcelona, PPU, 1994), los dos volúmenes de Cine Español. Una historia por autonomías (Barcelona, PPU, 19961998), el ensayo antropológico de José Ángel Garrido, Minorías en el cine. La etnia gitana en la pantalla (Barcelona, Publicacions Universitat de Barcelona, 2003), la investigación Balcázar Producciones Cinematográficas. Más allá de Esplugas City, original de Rafael de España y Salvador Juan i Babot, editada por la misma UB en 2005, con la colaboración del Ayuntamiento de Esplugues de Llobregat; la tesis de Francesc Sánchez Barba, Brumas del franquismo. El auge del cine negro español (1950-1965); o las nuevas monografías de Rafael de España, De La Mancha a la pantalla. Aventuras cinematográficas del ingenioso hidalgo, y de José Ángel Garrido, Empezaré contando el final. Cine en blanco y negro del siglo XX, todos editados por la UB en 2007.

Por eso, refiriéndose al cine de ficción, el especialista Jean Tulard se pronunció así en 1982:

La ficción histórica es raramente interesante en un primer grado, salvo obras como Enrique V (Laurence Olivier, 1944). Pero en un segundo grado, su interés es grande. He mostrado como los filmes consagrados a Napoleón son normalmente el reflejo de una ideología o las preocupaciones de una época. El simple film de ficción puede introducir un testimonio sobre la sociedad, pues hace de reflejo ${ }^{21}$.

Una sistematización de los diferentes modos de aproximarse al cine como instrumento didáctico de la Historia Contemporánea y medio de investigación histórica puede ser útil para clarificar mejor esta valoración.

\footnotetext{
${ }^{20}$ Las Actas se publicaron al año siguiente: International Conference on War, Film and Society. Proceedings edited by J. M. Caparrós Lera, S. Alegre \& Ll. Anyó, en Film-Historia, vol. III, núm. 1-2 (1993), textos en inglés, castellano y catalán.

${ }^{21}$ Jean Tulard, "Points de vue sur les rapports de l'Histoire et le Cinéma", en Les Cahiers de la Cinémathèque, núm. 35-36 (1982), pp. 17-18, monográfico sobre cine histórico. Cfr. también su artículo "Napoléon à l'écran", en La revue du Cinéma/Imagen et Son/Écran, núm. 373 (1982), pp. 123-128.
} 


\section{Reflejo de las distintas épocas a través del film}

Son aquellas películas que, sin una voluntad directa de "hacer Historia", poseen un contenido social y, con el tiempo, pueden convertirse en testimonios importantes de la Historia, o para conocer las mentalidades de cierta sociedad en una determinada época.

Un ejemplo claro lo tenemos en las obras del movimiento neorrealista (Roma, città aperta, Paisà, del referido Rossellini, o El limpiabotas y Ladrón de bicicletas, del binomio De Sica-Zavattini), e incluso en el cine de Éric Rohmer, quien desde sus denominados "Seis cuentos morales" (1962-1972), “Comedias y proverbios" (1980-1987) hasta los "Cuentos de las cuatro estaciones" (1989-1998) no ha hecho más que estudiar el comportamiento pequeño-burgués de una juventud intelectual francesa con vocación de etnólogo; o el genial Woody Allen, que con sus filmes está ofreciendo un retrato de la sociedad norteamericana contemporánea, especialmente de cierto mundo intelectual de Manhattan.

Asimismo, habría que situar en esta primera clasificación buena parte de los filmes de la escuela soviética de los años veinte (por ejemplo, La huelga, de Eisenstein, que data de 1924 y evoca una huelga en la etapa zarista), o aquellas películas basadas en obras literarias que reflejan una época y unos tipos que hoy ya forman parte del pasado histórico (tal es el caso, por no ir más lejos, de Las uvas de la ira, de John Ford, según la novela de Steinbeck y rodada en 1940, que reproduce el clima de la Depresión USA). Sin olvidarnos del cine español de los años del franquismo (primordialmente, los filmes de Bardem y Berlanga), que puede ser un catalizador del período, así como las cintas de nuestra democracia. E incluso los mismos filmes "serios" de ciencia-ficción (2001: Una odisea del espacio, Blade Runner, Matrix) pueden apuntar hipótesis sobre el mañana o acerca de los miedos e incertidumbres del hombre contemporáneo en torno al siglo venidero.

A estas películas el historiador Marc Ferro las denomina de reconstrucción histórica, pues son filmes que retratan a la gente de una época, su modo de vivir, sentir, comportarse, de vestir e incluso de hablar. Obviamente constituyen, sin pretenderlo, testimonios de la Historia Contemporánea. Filmes de ficción -o aparentemente de ficciónque requieren ya la atención de historiador, investigador o pedagogo. 


\section{La ficción histórica}

Cabe enclavar aquí aquellos títulos que evocan un pasaje de la Historia, o se basan en unos personajes históricos, con el fin de narrar acontecimientos del pasado aunque su enfoque histórico no sea riguroso, acercándose más a la leyenda o al carácter novelado del relato.

Tal es el caso, indiscutiblemente, del cine de Hollywood. Y de filmes míticos como Lo que el viento se llevó (1939). Películas que ofrecen, al mismo tiempo, una idealización del pasado, de cómo lo veía en esa época la industria hollywoodiense, dentro de las constantes del género tradicional y de sus intereses -también comerciales-, siguiendo las modas de un período o el estilo de determinada productora; como, por ejemplo, la versión de Los tres mosqueteros (1948), de George Sidney, para la Metro.

Estas películas, denominadas de género y algunas de gran calidad cinematográfica (recuérdese, si no, la gran tradición del cine histórico inglés, con cintas modélicas como Un hombre para la eternidad, realizada en 1966 por Fred Zinnemann), son dignas representantes del film-espectáculo y utilizan el pasado histórico únicamente como marco referencial, sin realizar habitualmente análisis alguno (léase el llamado "cine de romanos", made in Hollywood o coproducido en Europa $^{22}$ ). No obstante, por su ambientación, escenarios y vestuario, etc., pueden tener cierto interés didáctico.

Aun así, los límites entre el siguiente y definitivo apartado es, en algunos casos, difícil de definir; como ocurre con las piezas de los asimismo británicos David Lean (¡quién no ha admirado de nuevo la "reconstruida" Lawrence de Arabia, modelo del tipo de cine histórico-novelado que ha cultivado este autor!: El puente sobre el río Kwai, Doctor Zhivago, La hija de Ryan, Pasaje a la India) y Richard Attenborough, con Gandhi (1982). Con todo, se trata de un género en crisis, pero imperecedero como tal ${ }^{23}$.

Estas películas cabría denominarlas con el término acuñado por el teórico y cineasta galo Jean-Pierre Comolli -asimismo profesor de cine en la Universidad de París-: filmes de ficción histórica ${ }^{24}$.

\footnotetext{
${ }^{22}$ Vid. los libros clásicos de Jon Solomon, Peplum. El mundo antiguo y el cine. Madrid, Alianza, 2003; Rafael de España, El Peplum. La antigüedad en el cine. Barcelona: Glénat, 1998; y Derek Elley, The Epic Film. Myth and History. Londres, Routledge \& Kegan Paul, 1983.

${ }^{23}$ Para este tema, son clarificadoras las obras del referido pionero Ángel Luis Hueso, Historia de los géneros cinematográficos, I. Valladolid, Heraldo, 1976; y Los géneros cinematográficos. Materiales bibliográficos y filmográficos. Bilbao, Mensajero, 1983.

${ }^{24}$ Cfr. sus reveladores artículos "Le passé filmé" y "Le fiction historique", en Cahiers $d u$ Cinéma, 277 y 278 (1977), pp. 5-14 y 5-16, respectivamente; revista de la que fue redactor-jefe.
} 


\section{Filmes de reconstitución histórica}

Son aquellos que, con una voluntad directa de "hacer Historia", evocan un período o hecho histórico, reconstituyéndolo con más o menos rigor, dentro de la visión subjetiva de cada realizador, de sus autores. Se trata, pues, de un trabajo artístico-creativo que está más próximo a la operación historiográfica moderna que al libro de divulgación.

Estos filmes de reconstitución histórica, siguiendo la terminología de Marc Ferro -no confundir con el término "reconstrucción", que no es lo mismo-, son obras fundamentales como fuentes de investigación histórica y como medio didáctico. Pero que precisan de un análisis riguroso para ver en qué sirven como nueva reescritura de la ciencia histórica.

En este sentido, podríamos citar numerosos títulos: desde la triple visión de la Revolución inglesa del siglo XVII que nos dan Cromwell (1970), de Ken Hughes, Winstanley (1975), del historiador Kevin Brownlow \& Andrew Mollo y Matar a un rey (2003), de Tim Roth, hasta la del Risorgimento italiano vista por Roberto Rossellini (Viva l'Italia, 1960; Vanina Vanini, 1961) y Luchino Visconti (Senso, 1954; El Gatopardo, 1963), o los diversos filmes y "lecturas" sobre la Guerra Civil española ${ }^{25}$, por no citar más temas de la Historia Contemporánea.

Por tanto, las películas de reconstitución histórica nos dicen más, a veces, de cómo pensaban o piensan los hombres de una generación y la sociedad de una determinada época sobre un hecho pretérito que del mismo referente histórico en sí; es decir, clarifican más el hoy o el ayer en que ha sido realizado el film que la Historia evocada. Se transforma así el director cinematográfico en historiador. $\mathrm{Y}$ el historiador que realiza filmes históricos, se convierte -utilizando ahora la terminología acuñada por el profesor John Grenville- en un filmmaker II, en un segundo realizador ${ }^{26}$.

Son muchos los ejemplos que podemos poner: desde las obras maestras de Jean Renoir La gran ilusión y La Marsellesa, realizadas bajo el influjo ideológico del Frente

\footnotetext{
${ }^{25}$ Vid. los recientes libros de Magí Crusells, La Guerra Civil española: Cine y propaganda. Barcelona, Ariel, 2003; y Cine y Guerra Civil española: Imágenes para la memoria. Madrid, JC, 2006.

${ }^{26}$ Cfr. su artículo en Paul Smith, op. cit., pp. 132-141. Vid. también la obra de Abrash, B. \& Sternberg, J. (eds.) Historians and Filmmakers: Toward Collaboration. Nueva York, Institute for Research History, 1983.
} 
Popular francés, hasta las diversas versiones de Napoleón, sin olvidarnos de las particulares visiones de la época revolucionaria soviética de S. M. Eisenstein ( $E l$ acorazado Potemkin, Octubre, La línea general) y del cine del "realismo socialista" del estalinismo (el referido Tchapaiev, Los marinos de Cronstadt y tantos otros), o las numerosas películas dedicadas a la guerra de Vietnam y al apartheid sudafricano (Grita libertad, 1987; Un mundo aparte, 1988), por no hacer tampoco exhaustiva la lista de temas y títulos.

De ahí que, para terminar, el cine de reconstitución histórica -o de "resurrección", como diría Max Weber- esté o se enrole más directamente al servicio de la Historia. Y que tales filmes resulten verdaderamente interesantes como fuente de investigación y reflejo de las mentalidades contemporáneas.

Sin embargo, en este tipo de filmes muchas veces se solapan los tres niveles referidos. Por ejemplo, Las uvas de la ira explica su tiempo -la Depresión USA, en el mundo rural-, reconstituye la Historia, pero no es un film de ficción histórica. Mientras que La Marsellesa explica también su tiempo -el Frente Popular galo-, es un film de ficción histórica y posee una clara voluntad de reconstituir la Historia; como también la película de Éric Rohmer, La inglesa y el Duque (2001), que estaría más en la línea revisionista de François Furet sobre la Revolución Francesa, o asimismo a caballo del biopic y de la Historia oral.

En definitiva, se trata de sustituir el medio: los cineastas, en lugar de escribir un libro, hacen textos de Historia Contemporánea a través de sus películas. Por eso, la interpretación de los filmes, para fijar su verdadero sentido, pertenece también al arte de la hermenéutica. 